\title{
Research on the Person-job Matching of Vocational College Students Based on Java
}

\author{
Hong Shi ${ }^{1, a^{*}}$, Shouqiang Sun ${ }^{2, b}$ \\ ${ }^{1}$ Qingdao Huanghai College, Qingdao, Shandong Province, China \\ ashh9478@163.com, ${ }^{\mathrm{b}} 250815959 @ q q . c o m$
}

Keywords: Java course; Teaching methods; Person-job matching

\begin{abstract}
The vocational college graduates can not find work which is related to the professional. This phenomenon results in the unfully utilization of the human resources and education resources. This situation have a great impact on individuals, businesses and society. To solve this problem, proposes a teaching method based on Java courses, which tap the students' cognitive potential through case analysis, project teaching, school-enterprise cooperation and the other ways. To "point" to "face", it is applied to the other computer professional courses. Classroom teachers can use this method to dig out the similar potential , then give the students guidance and training, then translate the potential to the skills, and then matching the skills with the future direction of employment. In the end, the students have the ability to work in person-job matching.
\end{abstract}

\section{Introduction}

In August 25, 2014, the Ministry of Education issued the "opinions on carrying out the pilot work of the modern apprenticeship system", this will improve the quality of vocational education and pointed out the direction of promoting college students' employment[1].

Theory of the Person- job matching main meaning is personal subjective conditions and the individual has certain possibilities of social vocational positions relative intensity, phase matching to select a suitable for personal career."Person- job matching" is to help individuals find their characteristics consistent with the occupation, in order to achieve a reasonable match between people and career[2].

Vocational college students faced life again after 3-4 years of study in the second choice employment. However, the reality is that many students admitted to the university after there is no clear job target, combined with the school of education system structure and the curriculum system setting unreasonable [3], They found that after graduation between knowledge and social demand, therefore, It is hard to find a match the professional work. Through the questionnaire, Interviewee is the a computer professional students, a total of 352 people, the results of the survey $38 \%$ of the people work in the computer general service, $52 \%$ of people in other service work, only $10 \%$ of the people engaged in the work of the computer software design.

It turns out, If you don't have a clear during learning of college students career planning, there is no goal and motivation, knowledge skill grasp not solid, the result is that the school learn knowledge from the actual demand, lead to the difficult employment problem, there is also some famous university graduates. This paper calls for the line of teachers to act, seize the opportunity of pilot implementation the modern apprenticeship, realize the guiding ideology of modern apprenticeship, common for professional career planning for college students and improve the students' skills, in order to better find work you love, and in the workplace can maximize their professional ability.

\section{Implementation process}

Based on "the Java language" course as an example, discussing how the college students can better grasp of the Java language during learning knowledge and skills, so that in the future to engage in work related to computer professional courses in the Java language. Through on-the-spot 
investigation, this article will be engaged in the Java language related work has carried on the summary and the textbook chapters.

Engaged in the Java language jobs. The Java software design and development staff; Java database design personnel;Java network design personnel;the Java software testing and maintenance personnel and so on.

Textbook content adjustment.Through the above four aspects, semester, this article is no longer constrained by the order of the textbook, but will again in the Java language has carried on the classified summary chapters, divided into the following several parts to explain and practice:Understand and grasp the basic knowledge of Java;To learn Java Swing graphical user interface design and the Java Applet small applications; Grasp the JDBC database operations; The web in Java application.

To redraw the content module, we need to guide students in the usual Java teaching, according to their different specialty practice accordingly, it is a long-term process of accumulation. Before the start of the new semester, therefore, in this paper, the field needed to research the business skills, talents, skills training data collection based on Java course, apply to the teaching, detailed teaching progress and examination mechanism, accordingly after each inspection result summary; Arrived at the end of the semester, through the development of small projects to assess each student's ability to master Java language skills, which they each of cognitive potential; Finally, by each student's comprehensive evaluation result, it is concluded that the analysis report.

\section{Teaching measures.}

(1) Case analysis. In the process of lecture at ordinary times, the teacher wants to give some more examples related to society, the enterprise needs, for instance, develop the smartphone software, and mobile phone games, and so on ,they are the application of the Java language, in this way can make students feel Java is really useful in reality, so you will learn it well.

(2) Project teaching method. In teaching, the usual practice to develop a few small projects, master some of the development process (project requirement analysis, coding, operation, testing, writing system, said a book, etc.), the acceptance, examination and results, this process is very important, must be strictly treated. Of course, in the face of the students in the development process of problem, teachers should give necessary guidance. In addition, the teacher must by spot check and questioning methods such as timely understand the students' experiment situation [4].

(3) University-enterprise cooperation and work-integrated learning. Positive to the brother institutions and external institutions for training, software development company, such as cooperation, through various channels to increase students' practice, USES the master train an apprentice way, learn and practice, improve their skills, they can put this to use, and truly realize and employment of seamless line in the future.

In order to let the students to fully understand and grasp the course content, improve the learning ability of software development and testing of Java course, in the last three weeks at the end of the semester, we take the initiative to contact to the outside has the qualification training institutions (such as: Neusoft education, NIIT education), let the students to accept a targeted training there. Let them really feel and school learning environment is different, the real experience training is employment. At the beginning of the training, we signed a cooperation agreement between colleges and training institutions [5], the provisions on both sides of the responsibilities, develop skills training project, ensure the quality of this will address some of the students in the study at ordinary times, and broaden their horizons, increase their skill levels. After a short training, the students were asked to finish one small independent development of the project. Master teachers and enterprise common to assessment of the project teams and individuals, will assess the performance of the public. To reward some innovation, excellent project. 


\section{Training of the inspection work}

Training of the comprehensive assessment including this semester usually special module to inspection and at the end of the semester project training conducted by two parts. In order to ensure project successfully completed, we need to do the following several aspects:

1.Form a team.Students may independently according to his be fond of of project development team, personnel is commonly 4 to 5 people, personnel of screening according to the project design and development, use of the application of database, network and software testing in four aspects, such as division of labor.

2. Project requirements and instructions.Project selecting for small-scale projects, all questions are asked the graphical user interface, the project team during the development project to ensure that the project can finish, can draw lessons from some key code, but it can't copy all the original code, must have the innovation, if there is a lot of copying or unfinished project, the project team members will be deemed to be unqualified.

3. Results submitted.At the end of the project, each team should demonstrate the development of the system, and submit all the source code, data files, and summarizes the document. Summary document at least including the project requirement analysis, function and interface design, key code instructions and each work done, etc.

4. Results evaluation of standard.

(1) Design and development project(35 points).The inspection requirements: Reasonable project requirements, considering comprehensively; The system structure is clear, distinct, easy to extend and maintenance, database skills, reasonable; Reasonable personnel allocation, a clear division of responsibilities and can work together.

(2) Database de sign (20 points). The inspection requirements: Skilled to create data tables, and set up more tables between the indexes, and can be smoothly connected data tables; Connect to the database (JDBC bridge connection) well, and can be operated against the database (insert, delete, and modify).

(3) The use of the network (15 points). The inspection requirements: Client and server Settings is reasonable, can smoothly into the Java program.

(4) Software testing and maintenance (20 points). The inspection requirements: According to requirements to write test plan, according to the characteristics of the project and customer requirements, process optimization design, and constantly improve the testing process to ensure the normal use of the software.

(5) Document summary (10 points). Complete content, format, readable, and simple maintenance; Reporting comprehensive, accurate time scale grasp, language fluency, to answer the question fluently and correctly.

5.Performance evaluation.Grading by teachers and master enterprise jointly according to project completion and defense rating for each member, and self-evaluation of students and mutual way between team members, through the form of the three average to determine the performance of each member, but members must have the obvious difference between the results, don't allow achievement appear the phenomenon of concentration, collect classified project evaluation results, it is concluded that each student's final examination results, as shown in Table 1.

Students from table 1 shows the corresponding module's performance,clearly see the evaluation result, some students and can see they are intuitive one of the outstanding ability. For example: from the table 1, We can see,performance in design and development aspects of the project: the prominent $\mathrm{Wu} \mathrm{Li}$ and Zhang Yi classmate,they are more than the average of the class in the module, their software design and development of basic skills are solid; In the aspect of database design: the comparison of performance is outstanding Jiang Xiao-qi,and so on.The table1 is only part of the information of the classmate, But they have very strong representative, If all the students grades, will have certain rules to follow.If this conclusion made a career plan recognition system,I think every student according to the system, find their employment direction is clear, and for the effort, struggle! 
Table 1 2014-2015 academic year the first semester grade 13 computer applications part of the comprehensive assessment of students

\begin{tabular}{|c|c|c|c|c|c|c|c|}
\hline \multirow[t]{2}{*}{$\begin{array}{c}\text { The project } \\
\text { name }\end{array}$} & \multirow[t]{2}{*}{$\begin{array}{l}\text { Student } \\
\text { id }\end{array}$} & $\begin{array}{c}\text { Design and } \\
\text { development } \\
\text { projects }\end{array}$ & $\begin{array}{c}\text { Database } \\
\text { design }\end{array}$ & $\begin{array}{c}\text { The usage } \\
\text { of the } \\
\text { network }\end{array}$ & $\begin{array}{c}\text { Software } \\
\text { testing and } \\
\text { maintenance }\end{array}$ & $\begin{array}{c}\text { Document } \\
\text { summary }\end{array}$ & \multirow[t]{2}{*}{$\begin{array}{l}\text { Total } \\
\text { score }\end{array}$} \\
\hline & & Average & Average & Average & Average & Average & \\
\hline \multirow{5}{*}{$\begin{array}{l}\text { The } \\
\text { supermarket } \\
\text { cash } \\
\text { register } \\
\text { system }\end{array}$} & 13001 & 33 & 15.7 & 13.3 & 15.7 & 8.3 & 85.7 \\
\hline & 13002 & 25.3 & 18.3 & 12.7 & 16.7 & 7.7 & 80.7 \\
\hline & 13003 & 26 & 14.7 & 11.3 & 16.3 & 8.7 & 77 \\
\hline & 13004 & 24.7 & 14.3 & 12.7 & 18.3 & 8.3 & 78.3 \\
\hline & 13005 & 31 & 15.7 & 11 & 16.3 & 7.7 & 81.7 \\
\hline \multirow{5}{*}{$\begin{array}{c}\text { Whack a mole } \\
\text { game }\end{array}$} & 13006 & 24 & 15.7 & 11.7 & 18.3 & 8 & 77.7 \\
\hline & 13007 & 32.3 & 16 & 12.3 & 17.3 & 7 & 85 \\
\hline & 13008 & 29 & 17.7 & 12.7 & 16.3 & 7.7 & 83.3 \\
\hline & 13009 & 27.3 & 18.7 & 12.3 & 18.3 & 7.7 & 84.3 \\
\hline & 13010 & 27 & 16.3 & 12 & 16 & 7.3 & 78.7 \\
\hline \multicolumn{2}{|c|}{ The highest score } & 33 & 18.7 & 13.3 & 18.3 & 8.7 & \\
\hline \multicolumn{2}{|c|}{ The lowest score } & 24 & 14.3 & 11 & 15.7 & 7 & \\
\hline \multicolumn{2}{|c|}{ The average score } & 27.97 & 16.3 & 12.2 & 16.97 & 7.83 & \\
\hline
\end{tabular}

\section{Conclusion}

In June 16, 2014 the Ministry of education and other six departments issued a"Notice of the modern vocational education system construction plan (2014-2020) ", which to intensify the reform of vocational education, improve the students' full employment provides powerful guarantee[6].

Through the tentative teaching reform in the course of Java language, not only exercise the students' development software skills and interests, and cultivate their ability to team work.Through the exercise also dig out their potential in different aspects.From point to the surface, and expand to the whole, on the other courses of computer science,if they can get similar results, these skills will match the employment direction in the future, thus for their future employment has a definite guiding significance.

\section{Reference}

[1] Information on http://www.gov.cn/xinwen/2014-09/05/content_2745818.html

[2] Han Zheng. The application of the theory of person job matching in the course of employment of graduates majoring in Chemical Engineering. Technology \& Management, 2012,pp.24-26

[3] He Chun-hua, Zhang Meng-li, Chen Hui. The current situation of university students' employment professional mismatch and analysis. Human resources management ,2011,pp.250-251.

[4] Liu Zai-ying, Yang Ping. "Java programming" course experimental teaching. The third conference on teaching management and curriculum construction, 2012.pp.207-210.

[5] Gao Xian-qiang, Wu Gang, Chen Li-ping. Java program design course teaching mode exploration and research [J]. Modern Computer,2013.pp.28-31.

[6] Information on http:/www.moe.gov.cn/ publicfiles/busin-ess/htmlfiles/moe/moe_630/

201406/170737.html 